\title{
The EFFects of Suburban DeVELOPMENT AND WOLF (CANIS LUPUS) RECOLONIZATION ON COYOTES (CANIS LATRANS) IN JACKSON HOLE, WYOMING.
}

\author{
$\longrightarrow \gamma$ \\ STANLEY H. ANDERSON $\downarrow$ WY COOPERATIVE RESEARCH UNIT $\downarrow$ LARAMIE \\ DOUG WACHOB $\downarrow$ TETON SCIENCE SCHOOL $\downarrow \mathrm{KELLY} \downarrow \mathrm{WY}$ \\ RACHEL WIGGLESWORTH $\downarrow$ NATHAN MCCLENNEN \\ UNIVERSITY OF WYOMING $\downarrow$ LARAMIE
}

\begin{abstract}
$\downarrow \quad$ ABSTRACT
A comparative study of coyote (Canis latrans) home range, activity, habitat use, and diet in Grand Teton National Park (GTNP) and residential/agricultural areas surrounding Jackson, Wyoming was begun in May 1998 and will continue until August 1999. Twenty-seven coyotes were captured and fitted with radio collars equipped with activity and mortality sensors. Eleven of the coyotes reside in and around the residential/agricultural areas while 15 of the coyotes range from Moran Junction south to the National Elk Refuge. One coyote has remained in Bridger-Teton National Forest near Upper Slide Lake. Marked coyotes were monitored three times a week in the summer and two times a week during the winter via radio telemetry. Preliminary data suggests that the home range size of coyotes in GTNP is larger than that of coyotes in developed areas. Activity levels appear to be lower in residential/agricultural areas during daylight hours. Coyote diet is currently being assessed via scat dissection, and prey availability was determined using Sherman live traps during the summer and early fall. Habitat use will be determined by overlaying coyote home ranges onto habitat maps. Vegetation plots were conducted in five habitat types (aspen, conifer, grass, riparian, sage) to determine vegetation structure. All of the above methods will be repeated in summer 1999. During winter 1999 , telemetry surveys and scat collection will continue. Additionally, snow tracking
\end{abstract}

surveys and coyote observations will be conducted to determine coyote group size and behavior. If time allows, relative density estimates and social organization will be determined. The intention of this study is also to collect baseline data on coyotes before and during wolf (Canis lupus) recolonization of Jackson Hole.

\section{$\downarrow \quad$ INTRODUCTION}

Historically, the expansion of coyotes (Canis latrans) from prairie regions of the western United States to throughout North America has coincided with increased human land development and the elimination of the wolf (Canis lupus) (Nowak 1979, Bounds 1994). Jackson Hole offers a unique opportunity to record the effects of wolf recolonization and residential/agricultural development on coyote populations. Grey wolves were reintroduced into Yellowstone National Park in 1995, and recently individuals and groups have made forays into the northern part of Jackson Hole. Additionally, significant development is occurring in the southern end of the valley. Although a number of coyote studies have been conducted in Jackson Hole in the past, there are still questions about coyote population parameters, habitat use, and prey use (Weaver 1977, Camenzind 1978, Bekoff and Wells 1980, Tzilkowski 1980). 
Few studies have specifically examined the differences between coyote populations in residential areas versus coyote populations in protected (relatively undeveloped) national park areas (Bounds and Shaw 1997). Maintaining open space and wildlife habitat at a time of rapid human development is a concern of many valley residents. An understanding of the effects of suburban development on coyotes is important for future management practices of not only coyotes, but other wildlife species as well. Specific changes in coyote populations could also provide information into methods of integrating suburban development and wildlife habitat.

Data collected during this study will reinforce information already being collected in other areas of wolf reintroduction in Montana and Yellowstone National Park (Crabtree unpub., Arjo 1997) and examine the additive effect of residential development. The immigration and establishment of wolves into Jackson Hole will be a natural experiment where the presence of wolves will be a treatment placed on coyote habitat use, population ecology, and behavior. The data from the study would be used as baseline information to compare with future data to be collected after wolves begin to interact with coyotes in the same area.

\section{$\downarrow$ OBJECTIVES}

\section{Primary Objectives}

1. Determine the difference in coyote home range size for coyotes in developed and undeveloped areas of Jackson Hole, WY.

2. Determine the difference in coyote activity level for coyotes in developed and undeveloped areas of Jackson Hole, WY.

3. Determine the difference in prey use for coyotes in developed and undeveloped areas of Jackson Hole, WY.

4. Determine the difference in coyote habitat use in developed and undeveloped areas of Jackson Hole, WY.

\section{Secondary Objectives}

1. Gather baseline data, and determine the changes seen in coyote prey use, habitat use, and social organization if wolves move south into Jackson Hole, WY.

2. Investigate differences in social organization between coyotes in developed and undeveloped areas of Jackson Hole, WY.

3. Determine relative densities of coyotes in developed and undeveloped areas of Jackson Hole, WY.

\section{METHODS AND RESULTS}

Study area

Jackson Hole has been divided into two study areas: the South Park/Wilson (SPW) area (south and west of the town of Jackson) and Grand Teton National Park (GTNP) east of the Snake River between Moran Junction and the southern entrance to the Park on Highway 89. A few inholdings remain in the Park and the town of Kelly is in the southeast corner. Grazing allotments are maintained for a few weeks in the spring and fall as cattle are moved to and from Bridger-Teton National Forest. The SPW study area is primarily an agricultural area combined with high and low density residential areas. Private landowners have been contacted and have given permission to use their land in conjunction with this study.

\section{General Methods}

A total of 27 coyotes were captured using \#3 Softcatch padded offset leghold traps (Woodstream Corp, Lititz, Penn) during May/June 1998 and September 1998. Sixteen coyotes were captured in the southern end of GTNP, and 11 coyotes were captured in areas surrounding Jackson and Wilson. A ketamine hydrochloride $(\mathrm{KHCl})$ and xilazine hydrochloride $(\mathrm{XHCl})$ mixture was used to sedate and anesthetize the coyotes during the marking procedure. Each coyote was fitted with a 3-year battery life radiocollar from Advanced Telemetry Systems ( $<3 \%$ of coyote body weight). The sex, weight, estimated age, condition, presence of scars and markings, dentition, and description of mammae were recorded for each coyote. Sex ratios and age rations were approximately equal for both areas. No significant differences were noted in the weight of coyotes between the two study areas. Results from blood sampling are pending analysis at the Wyoming State Wildlife Veterinary Lab in Laramie, WY. Trapping was done in accordance to Wyoming Game and Fish and Grand Teton National Park guidelines.

Development will be measured from aerial photographs as houses per $\mathrm{km}^{2}$ and estimated people per $\mathrm{km}^{2}$ (Quinn 1997). Data collection will be divided up into four seasons based on known coyote biology: pair formation (1 Jan - $15 \mathrm{Mar}$ ), gestation (16 Mar $30 \mathrm{Apr}$ ), pup-rearing (1 May - 31 July), and dispersal (1 Aug- 31 Dec).

\section{Home range and movement}

Intensive monitoring of radiocollared coyotes began in July 1998 and will continue through August 1999. During summer 1998, six telemetry sessions, 
three per study area, were completed each week. During fall 1998 and winter 1999 four telemetry sessions, two per study area per week are being conducted. Telemetry locations are determined with hand held telemetry antennae systems. Predetermined routes and stations are used to attain point locations in a minimum duration interval. Both hourly and diurnal survey times have been determined randomly to cover all parts of the 24-hour period. Telemetry locations will give data for the determination of home range size, movement, activity, mortality, and habitat use. Bearings are plotted with the triangulation program LOCATE II (Pacer, Truro, Nova Scotia, Canada) on a palmtop computer (Hewlett-Packard 200LX) in the field. This program allows for the determination of a sufficient minimum error on each location. Analysis of home range data is done using an adaptive kernel method on the software program RANGES V (Kenward and Hodder, 1992).

Average error ellipse for all positions acquired was $0.153 \mathrm{~km}^{2}$ and the mean time to take sufficient bearings to achieve a location was 12.5 minutes. Initial results indicate that home ranges in the residential/agricultural areas are significantly smaller than those home ranges in the national park for the coyotes that have been marked in this study ( $\mathrm{p}<$ 0.05 , two sample t-tests). Mean home range size in the residential/agricultural area was $16.72 \mathrm{~km}^{2}(75 \%$ adaptive kernel). Mean home range size in GTNP was $62.25 \mathrm{~km}^{2}$ (75\% adaptive kernel). Due to some coyotes being captured in fall 1999, some home ranges may have been calculated without sufficient points to be valid.

\section{Habitat use}

The two study areas will be compared in terms of coyote selection of home range. Habitat types have been classified by major vegetation type: aspen, conifer, sage, grassland, and riparian. Habitat classifications will also include open, forested, edge, and proximity to nearest road or human dwelling. Home range selection will be described by quantifying the percent of total habitat types found within the study area. Home ranges will be determined for each of the radiocollared coyotes in each study area using radio telemetry. If sufficient locations with a error polygon $\leq .05 \mathrm{~km}^{2}$ are obtained, coyote selection of habitat use within their home range will be determined by plotting individual coyote locations on the vegetation map and recording habitat type (Gese et al. 1988). Specific vegetation characteristics of each habitat type were measured to investigate what coyotes are selecting for within each habitat. One hundred circular vegetation plots with $11.3 \mathrm{~m}$ in radius were measured in both study areas during summer
1998. Measurements included aspect, slope, sightability, ground cover, canopy cover, tree DBH, and small mammal abundance (Koehler and Hornocker 1991, Litvaitis et al. 1986). Habitat use will be analyzed with the geographic information system (GIS) software Arcview, Arcinfo, and aerial photographs. Landscape habitat variables will include distances to specific habitat features and coverage of vegetation types.

\section{Prey Utilization}

Over 400 pieces of scat have been collected along fixed transects and opportunistically in the two study areas. Scat transects range from $1.5-3 \mathrm{~km}$ in length and are found along dirt roads, unused twotracks, and trails. The transects are walked once every one to two months. Scat is stored in labeled paper bags and is awaiting analysis. Kelly's (1991) method will be used for scat analysis because existing techniques, such as visual estimate of percentage of prey remains in scat may not accurately characterize coyote diets (Kelly 1991, 1997). Skeletal remains will be used to identify species present in each scat, and hair samples will be used to apportion the prey items present in a scat. Skeletal remains will be identified by comparing skeletal prey remains with known collections from the Murie collection at the Teton Science School along with identification guides. Hair will be identified through methods of Tom Moore (pers. comm.) and Moore et al. (1974). Prey items will be identified to species where possible. Plant species will also be identified. PROGRAM SCAT (Kelly 1997) will be used in conjunction with correction factors to estimate the "amount of prey represented by a scat" (Kelly 1997).

Prey availability is being assessed in both study areas. Small mammal trapping (Sherman live traps) was used to determine relative abundance of small mammals. A total of 1000 trap nights were conducted in each study area during summer 1998 and again in early fall 1998. Results from these surveys are awaiting analysis. Coyote use of elk (Cervus elaphus) and deer (Odocoileus spp.) will be determined by scat analysis, by direct observation from observation points, and by opportunistic viewing. Predation attempts on ungulates and scavenging on ungulate carcasses will be observed. Group sizes of predating and scavenging coyotes will be measured (Gese and Grothe 1995). Data on availability of deer and elk carcasses and carrion will be obtained from GTNP, the National Elk Refuge, and Wyoming Game and Fish (Weaver 1977, 1979). Hunter harvest data will be used as well as mortality data from ongoing Park and Refuge studies 


\section{Activity}

Activity sensors on the radiocollars allow for the determination of activity in a monitored coyote. During random telemetry surveys for home range determination, an activity level is assessed for each bearing. Activity levels will be verified against visual observations during winter 1999. Initial results indicate that coyotes in the southern study area are less active during daylight hours and more active during early evening hours than those coyotes in Grand Teton National Park. Analysis was done by comparing mean activity level at each hour of the 24 hour period ( $p<$ 0.05 , paired t-tests).

\section{Group Size}

Radio telemetry will facilitate systematic visual observation in winter 1998-99 by allowing positive pack and individual identification. Direct open-field observations of coyotes combined with radio-telemetry during daylight hours will permit assessment of group size, litter size, possible dominance hierarchy, predation, and wolf-coyote interactions. Opportunistic sightings of coyotes, in addition to systematic behavioral observations, will provide information on pack locations, effective group size, and social interactions. Coyote social groups are highly visible in open field situations, at carcasses during the winter, and at dens in the spring. Recognition of individual pack members may provide an additional tool for pack census and density estimates.

Density

Scent-stations will be established and monitored for a three day period during spring 1999 following the methodology of Knowlton (1984). Twenty transects will be established in each study area. Each transect will consist of 10 scent stations over $2.7 \mathrm{~km}$ (one station every $0.3 \mathrm{~km}$ ). A station consists of a one-meter diameter sand circle with a scent in the middle (fatty acid scent or sardines on a cottonball). On the three following days after scent station establishment, all transects will be checked and the number of visited stations and operable stations will be recorded. On those stations that have been visited, tracks will be erased and sand replaced if needed. The index will be obtained by dividing the number of stations visited by the number of operable stations multiplied by 1000 (Knowlton 1984). Analysis will be done by comparing the difference between the means of all index values for all transects in each study area using a t-test.

Tracking surveys will be the only index used during the winter months. At least $20 \mathrm{~km}$ of transects will be used in each study area during the winter months. Transects will be checked 1-2 days following each snowfall. Each set of tracks that crosses the transect will be recorded along with group size, location, and habitat type. Specifications will be established to determine coyote tracks from fox and dog tracks. The index will be calculated as the number of tracks divided by the total kilometers of transects. The date, time, days since last snowfall, temperature, and cloud cover will also be recorded each time a transect is completed. Analysis will be done using a least squares mean between the two study areas (O'Donaghue, 1997). The means of the covariates (date, days since last snowfall, time, temperature, and cloud cover) will be used.

\section{Demography}

Mortality will be estimated by the mortality rates of collared coyotes and visual confirmation. Estimation of pup production will involve visual observations and possibly time lapse video photography of den sites. As of December 1999, no mortalities of marked coyotes have been recorded.

\section{$\downarrow$ COOPERATION}

This study is being carried out as a joint venture of the Wyoming Cooperative Fish and Wildlife Research Unit (COOP) and the Teton Science School (TSS). Funding has been attained from the Wyoming Cooperative Fish and Wildlife Research Unit, the Teton Science School, the University of Wyoming, and the University of Wyoming-National Park Service Research Station (AMK Ranch). In-kind donations in the form of radios and outdoor equipment have been obtained from various Wyoming businesses.

\section{$\downarrow \quad$ Literature Cited}

Arjo, W. M., R. R. Ream, D. H. Pletscher. 1997. Abstract: The effects of wolf recolonization on coyote behaviors, movements, and food habits in northwestern Montana. Wildlife Soc. $4^{\text {th }}$ Annual Conference. Snowmass, CO.

Bekoff, M., and C. M. Wells, 1980. Social ecology of coyotes. Scientific American. April. pp. 130-148.

Bounds, D. L. 1994. Managing coyotes in U.S. National Parks: Human-coyote interactions. Natural Areas Journal. 14:280-284. 
, and W. W. Shaw. 1997. Movements of suburban and rural coyotes at Saguaro National Park, Arizona. Southwest Naturalist 42 (1): 94-121.

Camenzind, F. J. 1978. Behavioral ecology of coyotes on the National Elk Refuge, Jackson, Wyoming. Pages 267-294 in M. Bekoff, ed. Coyotes: biology, behavior, and management. Academic Press, New York, N.Y.

Gese, E. M., O. J. Rongstad, and W. R. Mytton. 1988. Home range and habitat use of coyotes in southeastern CO. J. Wildl. Manage. 52(4):640-646.

and S. Grothe. 1995. Analysis of coyote predation on deer and elk during winter in Yellowstone National Park, Wyoming. American Midland Naturalist. 133: 36-43.

Kelly, B. T. 1991. Carnivore scat analysis: an evaluation of existing techniques and the development of predictive models of prey consumed. M. S. Thesis. University of Idaho, Moscow. 200 pp.

, and E. O. Garton. 1997. Effects of prey size, meal size, meal composition, and daily frequency of feeding on the recovery of rodent remains from carnivore scats. Can. J. Zool. 75: 1811-1817.

Kenward, R. E., and K. H. Hodder. 1996. RANGES $\mathrm{V}$ : an analysis system for biological location data. Inst. Terrestrial Ecol., Furzebrook Res. Stn. Wareham, Dorset, U. K. 66 pp.

Knowlton, F. F.. 1984. Feasibility of assessing coyote abundance on small areas. Work Unit 909:01. Denver Wildlife Research Center. $13 \mathrm{pp}$.
Koehler, G. M. and M. G. Hornocker. 1991. Seasonal resource use among mountain lions, bobcats, and coyotes. J. Mammal. 72: 391-396.

Litvaitis J. A., J. A. Sherburne, J. A. Bissonette. 1986. Bobcat habitat use and home range size in relation to prey density. J. Wildl. Manage. 50: 110-117.

Moore, T. D., L. E. Spencer, and C. E. Dugnolle. 1974. Identification of the dorsal guard hairs of some mammals of Wyoming. Wyoming Game and Fish Department. Bull. 14. 177 pp.

Nowack, R. M. 1979. North American Quarternary Cais. University of Kansas, Museum of Natural History. Monograph 6.: 150-162.

O'Donaghue, M., S. Boutin, C. J. Krebs, and E. J. Hofer. 1997. Numerical responses of coyotes and lynx to the snowshoe hare cycle. Oikos 80: $150-162$.

Quinn, T. 1997. Coyote food habits in three urban habitat types of western Washington. Northwest Science. 71:1-5.

Tzilkowski, W. M. 1980. Mortality patterns of radiomarked coyotes in Jackson Hole, Wyoming. Ph.D. Thesis. Univ. Mass., Amherst. 67 pp.

Weaver, J. L. 1977. Coyote food-base relationships in Jackson Hole, Wyoming. M.S. Thesis, Utah St. Univ., Logan, UT. 88 pp.

1979. Influence of elk carrion upon coyote populations in Jackson, Wyoming. Pages 152-157. in Boyce and Hayden-Wing. Symposium on North American elk ecology, behavior, and management. University of Wyoming, Laramie, Wyoming. 